\title{
Change in mass and damping on vertically vibrating footbridges due to pedestrians
}

\author{
Georgakis, Christos T.; Jørgensen, Nina Gall
}

Published in:

Proceedings of the SEM IMAC XXXI Conference

Publication date:

2013

Link back to DTU Orbit

Citation (APA):

Georgakis, C. T., \& Jørgensen, N. G. (2013). Change in mass and damping on vertically vibrating footbridges due to pedestrians. In Proceedings of the SEM IMAC XXXI Conference

\section{General rights}

Copyright and moral rights for the publications made accessible in the public portal are retained by the authors and/or other copyright owners and it is a condition of accessing publications that users recognise and abide by the legal requirements associated with these rights.

- Users may download and print one copy of any publication from the public portal for the purpose of private study or research.

- You may not further distribute the material or use it for any profit-making activity or commercial gain

- You may freely distribute the URL identifying the publication in the public portal

If you believe that this document breaches copyright please contact us providing details, and we will remove access to the work immediately and investigate your claim. 


\title{
Change in mass and damping on vertically vibrating footbridges due to pedestrians
}

\author{
Christos T. Georgakis ${ }^{1}$, Nina G. Jørgensen ${ }^{1}$ \\ ${ }^{1}$ Department of Civil Engineering, Technical University of Denmark, Building 118, Brovej, DK-2840 \\ Kgs. Lyngby, Denmark email: cg@byg.dtu.dk, ninga@byg.dtu.dk
}

\begin{abstract}
Pedestrian-induced footbridge vibrations are an issue that bridge designers often have to contend with. A plethora of research in recent years has led to the development of load models and procedures that allow for the determination of footbridge response. Nonetheless, measured footbridge responses often deviate from those predicted. One of the main deficiencies of the existing models and guidelines is the exclusion of the effect of changes in the footbridge's dynamic properties due to the presence of pedestrians. More specifically, any change in mass and/or damping that a pedestrian might introduce to a bridge will affect the bridges overall dynamic response. This effect is an element of what is often referred to as human-structure interaction. In this paper, the results of an experimental study to determine the change in mass and damping of a vertically vibrating footbridge due to traversing pedestrians are presented.
\end{abstract}

Keywords: vertical footbridge vibrations, mass, damping

\section{INTRODUCTION}

The majority of footbridges designed during the $20^{\text {th }}$ century were designed in a purely utilitarian manner, with the goal being the creation of a path for pedestrians to traverse between two points, without the impediment of e.g. vehicle traffic or bodies of water. Towards the end of the $20^{\text {th }}$ century this changed, as footbridge construction began to be viewed by architects and city planners as a tool for urban regeneration and as a means to create landmark structures and large-scale "sculptures". This shift in design philosophy, together with a reassessment our energy-intensive transportation infrastructure, has lead to a change in the perceived importance of footbridges. As a consequence, designers and engineers are paying greater attention to the aesthetic details and the servicability of footbridges, making sure that they are both beautiful and "comfortable".

Although footbridge comfort is often difficult to define, vibration comfort criteria within international codes and guidelines do exist [1,2]. More often than not, the same codes and guidelines offer a means to assess the level of footbridge vibrations. Nevertheless, even though these codes and guidelines have often existed and been used, in some cases, for decades, it is not until recently that researchers and engineers have produced load models and procedures that allow for a more reasoned determination of footbridge response [3]. Still, even with the recent advances in load models and response prediction, measured footbridge responses often deviate from those predicted.

One of the main deficiencies of the new generation of models and guidelines is the exclusion of the effect of changes in the footbridge's dynamic properties due to the presence of pedestrians. Any change in mass and/or damping that a pedestrian might introduce to a footbridge will affect the footbridges overall dynamic response. This effect is an element of what is often referred to as human-structure interaction.

To the authors' knowledge, there has only been one other reported systematic attempt to determine the change of a footbridge's dynamic properties due to the presence of walking humans. Zivanovic et al. 0 showed an increase in damping of a $11.3 \mathrm{~m}$ long concrete footbridge, as a function of the number of traversing pedestrians. Unfortunately, the study was unsuccessful in generalizing the results in manner that would allow for their use on any footbridge or similar structure. Furthermore, no attempt was made to quantify a potential change in equivalent structural mass, due to the presence of pedestrians.

In this paper, the authors present the results from an experimental campaign, aimed at determining the changes in mass and damping of a vertically vibrating footbridge due to pedestrians. The results are presented in a generalized manner, i.e. as the added/subtracted mass or concentrated damping per single pedestrian, at varying amplitudes of vibration and for varying probabilities of occurrence.

\section{METHODOLOGY}

The methodology used for the determination of the changes in mass and damping of a footbridge due to pedestrians is conceptually simple. First, a detailed experimental modal analysis of the laboratory footbridge without pedestrians is undertaken. From this, eigenmodes, frequencies, modal mass and damping of the empty footbridge are determined. Next, a hydraulic actuator is attached to the center of the footbridge; the purpose of this being the displacement- and frequencycontrolled excitation of the footbridge at mid-span. The dynamic properties of the footbridge are once again determined through vertical dynamic actuation of the footbridge at mid-span. An excitation frequency sweep around the first natural frequency of the empty footbridge reveals the frequency at which minimum effort is needed for the actuator to excite the footbridge vertically. Once it is established that the footbridge's dynamic properties have not changed due to the introduction of the actuator, streaming pedestrians with varying flow rates are introduced to the footbridge. Longer measurements of the pedestrian-induced loads ensure that the excitation is stationary in nature. For the experiments reported herewith, vertical excitation was undertaken at predetermined bridge mid-span amplitudes of 1,5 and $10 \mathrm{~mm}$. The observed shift in frequency can be attributed to two separate effects, a change in structural mass and/or a change in damping. 
If the vibration of the footbridge is restricted to motion in the first eigenmode, then the damped circular frequency of the empty footbridge will be:

$$
\omega_{D}=\sqrt{\frac{k\left(1-\xi^{2}\right)}{m}}
$$

where $k$ is the modal stiffness, $m$ is the modal mass and $\xi$ is the modal damping ratio of the footbridge's first eigenmode. When pedestrians are traversing over the footbridge, a change in the footbridge's dynamic properties leads to a new damped circular frequency:

$$
\omega_{D}^{\prime}=\sqrt{\frac{k^{\prime}\left(1-\xi^{\prime 2}\right)}{m^{\prime}}}
$$

where $k^{\prime}$ is the modified modal stiffness, $m^{\prime}$ is the modified modal mass and $\xi^{\prime}$ is the modified modal damping ratio of the footbridge's first eigenmode. As the footbridge's modal stiffness is expected to remain constant, it is assumed that $k^{\prime}=k$. By solving equation (2) for $k^{\prime}$ and substituting into equation (1), the footbridge's new modal mass as a result of the traversing pedestrians can be expressed as:

$$
m^{\prime}=m \frac{\omega_{D}^{2}}{\omega_{D}^{\prime 2}} \frac{\left(1-\xi^{\prime 2}\right)}{\left(1-\xi^{2}\right)}
$$

The footbridge's modified damped circular frequency is readily determined by performing an excitation frequency sweep, at predetermined displacement levels, close to the original circular frequency of the unloaded footbridge. The frequency at which the work required by the actuator is minimized is the modified natural frequency for the excited eigenmode.

The modified damping can be determined indirectly by computing the energy dissipated per vibration cycle by the footbridge. The energy dissipated per cycle by the footbridge is a function of the load imparted by the actuator and the velocity of the footbridge at the point of load application, so that [5]:

$$
E_{D}=\int_{0}^{T} F(t) v(t) d t
$$

where $F(t)$ is the dynamic load from the hydraulic actuator, $v(t)$ it the vertical velocity of the footbridge at mid-span, and $T$ is the period of one cycle. The modified footbridge damping, expressed as an equivalent viscous damping ratio as a percentage of critical, is then found as 0 :

$$
\xi^{\prime}=\frac{E_{D}}{2 \pi m^{\prime} \omega_{D}^{\prime 2} X^{2}}
$$

Where $X$ is the maximum mid-span displacement of the footbridge. It can be seen from Eq. (5) that the equivalent viscous damping ratio is a function of the modified mass and, as such, the modified modal mass of the footbridge cannot be determined without employing an iterative approach.

\subsection{Pedestrian mass and damping coefficient}

To generalize the findings, the individual contributions of each pedestrian to any potential change in footbridge mass and damping are determined. The change in the footbridge's damping ratio attributable to the pedestrians will be:

$$
\xi_{A}=\xi^{\prime}-\xi
$$

The cumulative damping coefficient for all pedestrians can be written as:

$$
c_{A}=2 m^{\prime} \xi_{A} \omega_{D}^{\prime}
$$

Assuming a uniform distribution of the pedestrian population on the footbridge, $c_{A}$ can also be written as:

$$
c_{A}=\int_{0}^{L} c_{p} N \phi(y)^{2} d y
$$

where $c_{p}$ is the damping coefficient of the individual pedestrian, $N$ is the number of pedestrians on the footbridge, and $\phi(y)$ is the mode shape of the eigenmode under examination. From Eqs (7) and (8), the damping coefficient of the individual pedestrian is found as:

$$
c_{p}=\frac{2 m^{\prime} \xi_{A} \omega_{D}^{\prime}}{N \int_{0}^{L} \phi(y)^{2} d y}
$$


Similarly, it can be found that the mass contribution of the individual pedestrian is:

$$
m_{p}=\frac{m^{\prime}-m}{N \int_{0}^{L} \phi(y)^{2} d y}
$$

\subsection{Experimental setup}

A simply-supported 16m-long steel double U-beam footbridge, located in the Structures Laboratory of the Department of Civil Engineering at DTU (Figs. 1,2) was used as the basis structure for the experiments. The longitudinal beam profiles were UNP 350, with UNP 200 crossbeams placed at $1400 \mathrm{~mm}$ intervals. For the experiments described herewith, masses were added to the footbridge crossbeams and to the center of the footbridge to increase the modal mass and thus decrease the footbridge's frequency to a level close to the expected mean pacing frequency of the pedestrians. The total mass of the footbridge was $5224 \mathrm{~kg}$.
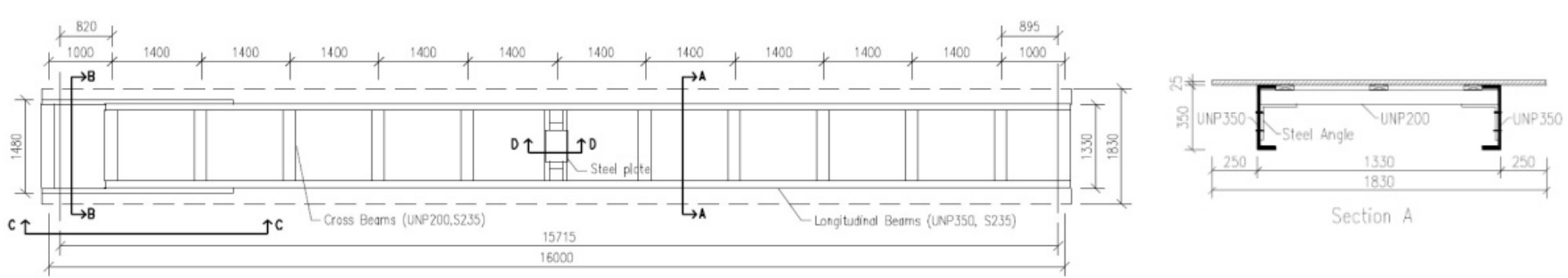

Figure 1a: Elevation and 1b: Cross-section of the laboratory footbridge structure.

The platform on which the pedestrians walked was made of medium density fiberboard (MDF) plates with a width of $1840 \mathrm{~mm}$. The plates were attached to the footbridge steel frame with screws. Wooden platforms of approximately $1.5 \mathrm{x}$ $1.5 \mathrm{~m}^{2}$ were constructed on either side of the footbridge to act as pedestrian launching platforms and turn-around areas. Stairs were made leading up to the platforms. The footbridge walking level was approximately $1.2 \mathrm{~m}$ above the laboratory floor. There was no hand railing on the footbridge.

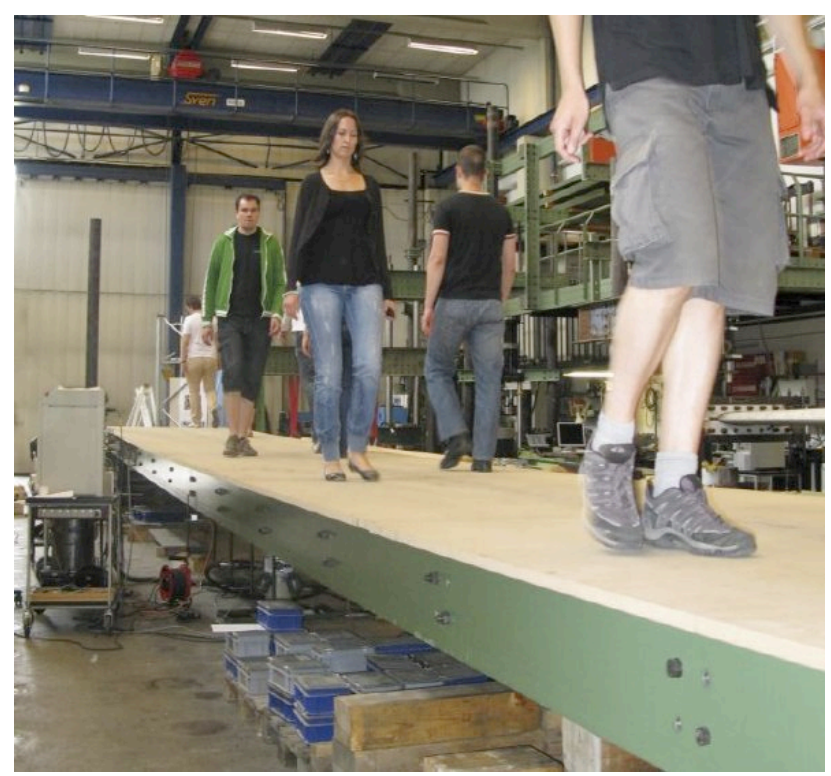

Figure 2: Pedestrians traversing the $16 \mathrm{~m}$ long DTU laboratory footbridge.

Actuation of the footbridge during the tests was provided by a $100 \mathrm{kN}$ Instron 8500 hydraulic actuator, placed vertically beneath the center of the bridge (see Figure 3). A calibrated Instron 8516 load cell was used to measure the force between the actuator and the footbridge throughout the tests.

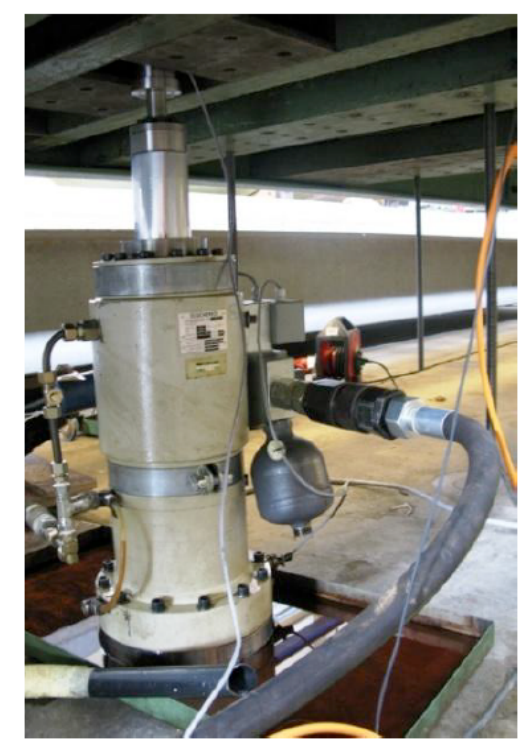

Figure 3: Actuator at footbridge mid-span with hinged load cell. 


\section{EXPERIMENTS}

\subsection{Footbridge modal analysis}

A modal analysis of the empty footbridge was undertaken to determine the modal mass, stiffness, damping, and mode shapes for the first several eigenfrequencies of the footbridge. The modal analysis was performed through a series of free-decay tests. For each test, a set of DC accelerometers were placed as reference accelerometers in the center of the bridge on either side and another set was moved along the bridge, from the center towards the supports. The accelerometers used were Bruel \& Kjær 4575 with a $2 \mathrm{~g}$ range.

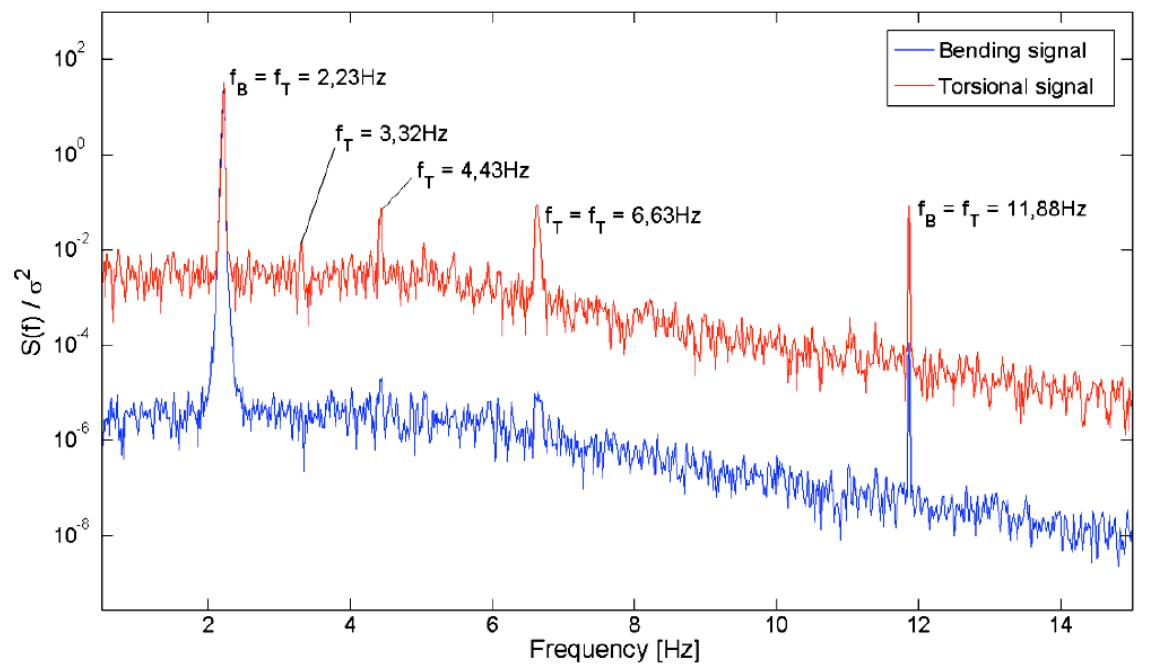

Figure 4: Normalized PSD of bending and torsional signals measured during the footbridge modal analysis

Figure 4 shows the normalized power spectral density (PSD) of a set of bending and torsional accelerations measured during the modal excitation. From this, the footbridge frequencies can be identified, for both bending and torsional modes. A finite element analysis of the footbridge identified the same modes, with small deviations in frequency. The first bending eigenmode was found to be near perfectly sinusoidal in shape.

The modal frequency and damping were both found to be amplitude dependent. Figure 5 shows the dependency of frequency on vibration amplitude, whilst Figure 6 shows the amplitude dependency of the damping of the empty bridge. The plotted points are a result of five independent vibration tests.

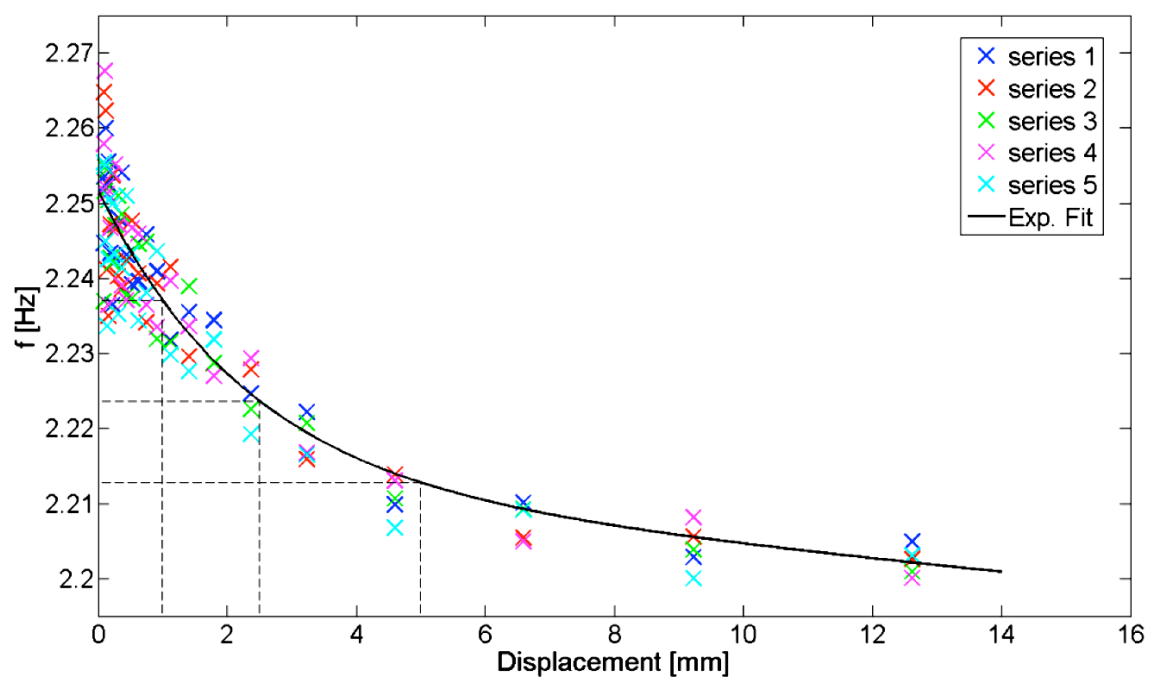

Figure 5: Amplitude dependent first natural frequency for the empty footbridge

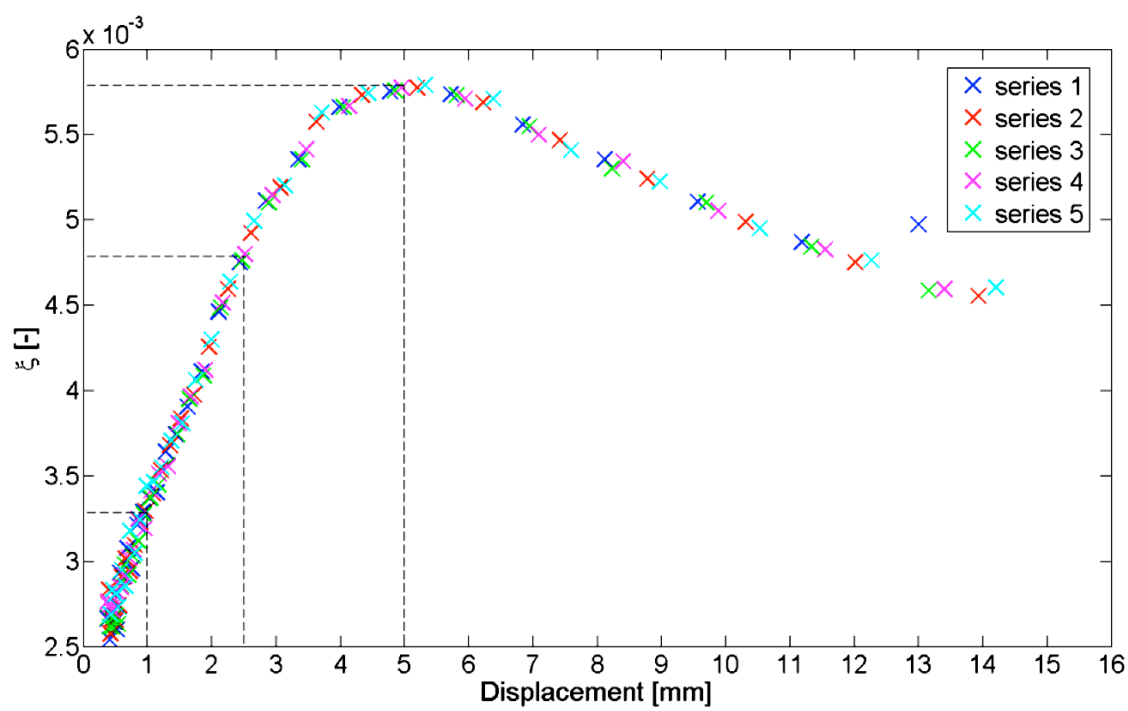

Figure 6: Amplitude dependent damping for the empty footbridge 
Frequency response curves were also established for the empty footbridge, once the actuator of Figure 3 was installed, but no discernable change in the structures modal properties could be measured.

\subsection{Pedestrian tests}

A series of Monte Carlo simulations were run to evaluate the minimum number of pedestrians and time that would be needed to ensure loading stationarity. The minimum number of pedestrians was found to be four, whilst the minimum test duration was found to be 180 seconds. During the tests, mean pedestrian flow rates were varied, but it was subsequently found that the change in footbridge mass and damping from each pedestrian was flow-independent. To vary the flow rates, tests were repeated with 4,7 and 10 pedestrians, leading to mean flow rates of approximately $\lambda=0.35,0.62$ and 0.88 ped/s. Pedestrians were allowed to walk in both directions along the bridge.

A frequency sweep was undertaken for each distinct mean flow rate and mid-span amplitude, to determine the natural frequency of the footbridge with the moving pedestrians on it. Tables 1,2 and 3 show the excitation frequencies for each flow rate, respectively.

Table 1: Excitation frequencies vs. amplitude for $\lambda=0.35$

\begin{tabular}{|c|c|c|c|c|c|c|c|c|}
\hline Amplitude [mm] & & & & Frequ & $\mathrm{y}[\mathrm{Hz}]$ & & & \\
\hline 1 & 2.086 & 2.136 & 2.155 & 2.174 & 2.192 & 2.211 & 2.230 & 2.280 \\
\hline 5 & 2.073 & 2.123 & 2.142 & 2.162 & 2.182 & 2.201 & 2.220 & 2.270 \\
\hline 10 & 2.029 & 2.079 & 2.097 & 2.115 & 2.134 & 2.152 & 2.170 & 2.220 \\
\hline
\end{tabular}

Table 2: Excitation frequencies vs. amplitude for $\lambda=0.62$

\begin{tabular}{ccccccccc}
\hline Amplitude [mm] & \multicolumn{10}{c}{ Frequency [Hz] } \\
1 & 2.022 & 2.072 & 2.104 & 2.135 & 2.167 & 2.198 & 2.230 & 2.280 \\
5 & 2.009 & 2.059 & 2.091 & 2.123 & 2.156 & 2.188 & 2.220 & 2.270 \\
10 & 1.965 & 2.015 & 2.046 & 2.077 & 2.108 & 2.139 & 2.170 & 2.220 \\
\hline
\end{tabular}

Table 3: Excitation frequencies vs. amplitude for $\lambda=0.88$

\begin{tabular}{|c|c|c|c|c|c|c|c|c|}
\hline \multirow{2}{*}{$\begin{array}{l}\text { Amplitude }[\mathrm{mm}] \\
1\end{array}$} & \multicolumn{8}{|c|}{ Frequency $[\mathrm{Hz}]$} \\
\hline & 1.980 & 2.030 & 2.074 & 2.118 & 2.162 & 2.206 & 2.225 & 2.300 \\
\hline 5 & 1.970 & 2.020 & 2.064 & 2.108 & 2.152 & 2.196 & 2.240 & 2.290 \\
\hline 10 & 1.950 & 2.000 & 2.044 & 2.088 & 2.132 & 2.176 & 2.220 & 2.270 \\
\hline
\end{tabular}

The distribution between male and female participants was 50/50 for the lowest and highest flow rates and 86/17 for $\lambda=0.62$. Participants for the first two flow rates wore mainly comfortable athletic shoes (trainers). For the highest flow rate, flip-flops or heals were worn mainly, instead of trainers. The mean pacing frequency of $f_{p}=1.38 \mathrm{~Hz}$ for all the tests was much lower than might be expected for the Danish population, where $f_{p}$ is closer to $1.83 \mathrm{~Hz}$. This is mostly likely due to the test environment and the physical and psychological constraints imposed by the narrow deck without handrails.

\section{RESULTS}

Intuitively, it might be expected that the average added mass per pedestrian is equivalent to the mass of each individual pedestrian. This is in fact what was found from the tests, with the average added mass per pedestrian being $102 \%$ their total individual mass. This value was found to be constant, regardless of flow rate and vibration amplitude or frequency tested.

In contrast to what has been previously reported for vibrations in the lateral direction [6], the pedestrians here were found to always add damping vertically to the bridge when walking across it. The measured added damping had some level of scatter in it, due to the stochastic nature of the pedestrian loading. Therefore, a statistical analysis of the damping per cycle was performed to evaluate the probability of occurrence of varying magnitudes of added pedestrian-attributable damping. For all vibration amplitudes and flow rates, it was found that the Weibull distribution was a best fit to the data. The Weibull probability density function for the pedestrian damping, $P\left(c_{p}\right)$, can be written as:

$$
P\left(c_{p} ; \mu, \kappa\right)=\frac{\kappa}{\mu}\left(\frac{c_{p}}{\mu}\right)^{\kappa-1} e^{-\left(c_{p} / \mu\right)^{\kappa}}
$$

where $\mu$ and $\kappa$ are the scale and shape parameters of the distribution. The mean, standard deviation and fractile values of the distributions describing the pedestrian damping coefficients for each flow rate and mean floor displacement (above $1 \mathrm{~mm}$ ) are presented in Tables 4-6. The scale and shape parameters of the distributions are also provided.

Table 4: Weibull distribution parameters describing the added pedestrian damping coefficients for $\lambda=0.35$

\begin{tabular}{ccccccccc}
$\begin{array}{c}\text { Mean amplitude } \\
{[\mathrm{mm}]}\end{array}$ & $\begin{array}{c}10 \% \\
{[\mathrm{~kg} / \mathrm{s}]}\end{array}$ & $\begin{array}{c}50 \% \\
{[\mathrm{~kg} / \mathrm{s}]}\end{array}$ & $\begin{array}{c}90 \% \\
{[\mathrm{~kg} / \mathrm{s}]}\end{array}$ & $\begin{array}{c}95 \% \\
{[\mathrm{~kg} / \mathrm{s}]}\end{array}$ & $\begin{array}{c}c_{p} \text { mean } \\
{[\mathrm{kg} / \mathrm{s}]}\end{array}$ & $\begin{array}{c}\sigma \\
{[\mathrm{kg} / \mathrm{s}]}\end{array}$ & $\begin{array}{c}\mu \\
{[-]}\end{array}$ & $\begin{array}{c}\kappa \\
{[-]}\end{array}$ \\
\hline 1.6 & 201.5 & 1381.8 & 3643.5 & 4472 & 1706.3 & 1339.3 & 2056.3 & 1.343 \\
3.2 & 40.7 & 770.2 & 2145.6 & 2645.7 & 966.3 & 817.1 & 1274.7 & 1.364 \\
\hline
\end{tabular}

Table 5: Weibull distribution parameters describing the added pedestrian damping coefficients for $\lambda=0.62$

\begin{tabular}{ccccccccc}
$\begin{array}{c}\text { Mean amplitude } \\
{[\mathrm{mm}]}\end{array}$ & $\begin{array}{c}10 \% \\
{[\mathrm{~kg} / \mathrm{s}]}\end{array}$ & $\begin{array}{c}50 \% \\
{[\mathrm{~kg} / \mathrm{s}]}\end{array}$ & $\begin{array}{c}90 \% \\
{[\mathrm{~kg} / \mathrm{s}]}\end{array}$ & $\begin{array}{c}95 \% \\
{[\mathrm{~kg} / \mathrm{s}]}\end{array}$ & $\begin{array}{c}c_{p} \text { mean } \\
{[\mathrm{kg} / \mathrm{s}]}\end{array}$ & $\begin{array}{c}\sigma \\
{[\mathrm{kg} / \mathrm{s}]}\end{array}$ & $\begin{array}{c}\mu \\
{[-]}\end{array}$ & $\begin{array}{c}\kappa \\
{[-]}\end{array}$ \\
\hline 1.6 & 197.2 & 1113.3 & 2903.5 & 3565.2 & 1366.8 & 1112 & 1590.8 & 1.318 \\
3.2 & 65.9 & 685.9 & 1930 & 2395.4 & 875.29 & 716.6 & 1072.4 & 1.287 \\
\hline
\end{tabular}


Table 6: Weibull distribution parameters describing the added pedestrian damping coefficients for $\lambda=0.88$

\begin{tabular}{ccccccccc}
$\begin{array}{c}\text { Mean amplitude } \\
{[\mathrm{mm}]}\end{array}$ & $\begin{array}{c}10 \% \\
{[\mathrm{~kg} / \mathrm{s}]}\end{array}$ & $\begin{array}{c}50 \% \\
{[\mathrm{~kg} / \mathrm{s}]}\end{array}$ & $\begin{array}{c}90 \% \\
{[\mathrm{~kg} / \mathrm{s}]}\end{array}$ & $\begin{array}{c}95 \% \\
{[\mathrm{~kg} / \mathrm{s}]}\end{array}$ & $\begin{array}{c}c_{p} \text { mean } \\
{[\mathrm{kg} / \mathrm{s}]}\end{array}$ & $\begin{array}{c}\sigma \\
{[\mathrm{kg} / \mathrm{s}]}\end{array}$ & $\begin{array}{c}\mu \\
{[-]}\end{array}$ & $\begin{array}{c}\kappa \\
{[-]}\end{array}$ \\
\hline 1.7 & 207.3 & 1083 & 2862.6 & 3532.3 & 1347.7 & 1055.6 & 1511.8 & 1.272 \\
3.2 & 72.2 & 593.3 & 1643.5 & 2037.3 & 754.5 & 605.1 & 900.6 & 1.281 \\
\hline
\end{tabular}

An examination of the distributions revealed similarities in the pedestrian damping coefficients from one flow rate to another. Therefore, it was found that an exponential fit could be made to the data to reveal amplitude-dependent and flow-independent pedestrian damping coefficients, $c_{p}$, for varying fractile levels. The exponential fit is of the form:

$$
c_{p}=a \cdot e^{b x}+c \cdot e^{d x}
$$

where $x$ represents the mean floor displacement in millimeters and $a, b, c, d$ are coefficients that are determined based on a least square fit. The coefficients are provided in Table 7. Substitution of the coefficients of Table 7 into Equation (12) leads to Figure 7, in which the amplitude-dependent pedestrian damping coefficient is plotted for each fractile.

\begin{tabular}{c|cccc}
\multicolumn{5}{c}{ Table 7: Coefficients for the exponential fit of Eq. (12) } \\
\hline \multirow{2}{*}{} & $10 \%$ & $50 \%$ & $90 \%$ & $95 \%$ \\
\hline$a$ & 2224.9 & 17457 & 72456 & 98698 \\
$b$ & -3.54 & -4.49 & -5.42 & -5.05 \\
$c$ & 622.08 & 2026.3 & 5101.5 & 6231.91 \\
$d$ & -0.76 & -0.35 & -0.32 & -0.32 \\
\hline
\end{tabular}

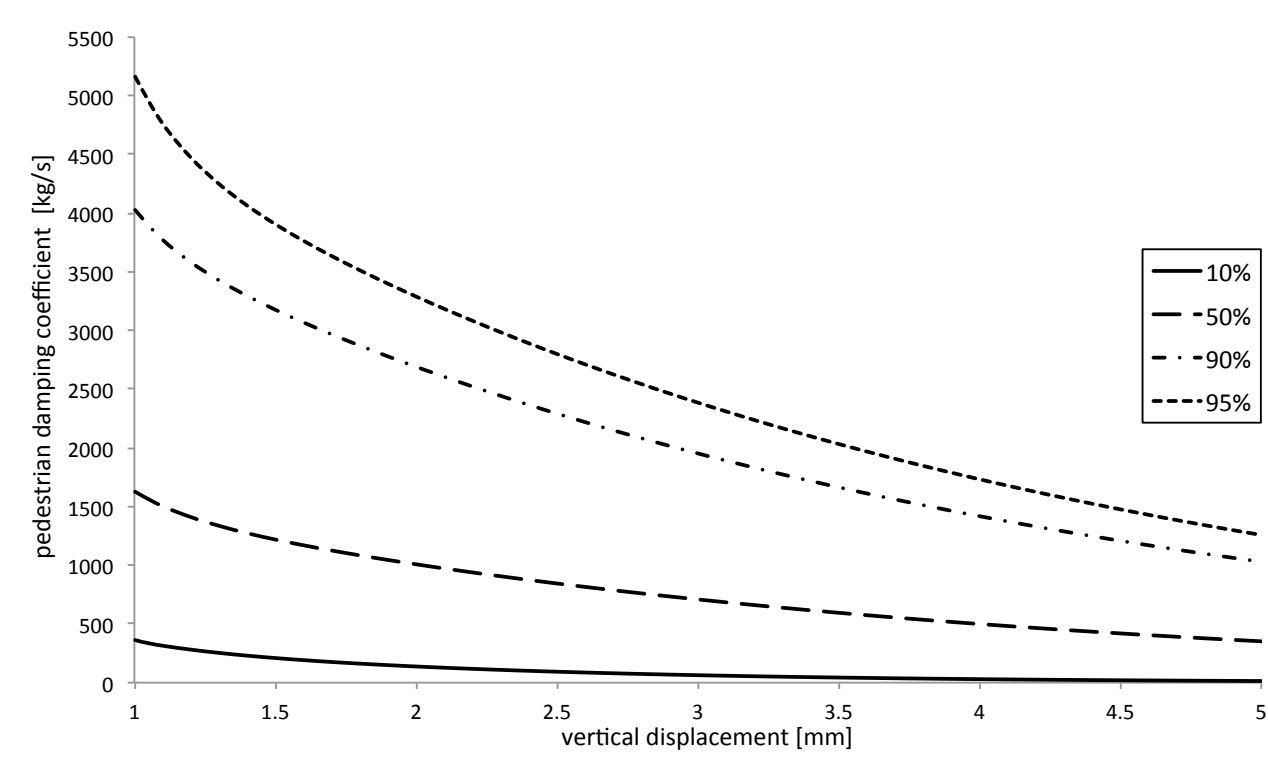

Figure 7: Amplitude dependent pedestrian damping coefficients for varying probability fractiles

As only three distinct vibration amplitudes were tested, it should be reasonable to suggest that the exponential fit of Equation (12) could be substituted with a linear fit, which might also be more conservative for design purposes for lower vibration amplitudes. Finally, Figure 7 reveals a reduction in pedestrian damping with amplitude of vibration. This indicates a change in the way pedestrians interact with a footbridge for larger vibrations.

For design purposes, a pedestrian may be treated as a moving point viscous damper, in which case a conservative fixed value of $c_{p}=500 \mathrm{~kg} / \mathrm{s}$ is suggested for moderate vertical vibrations of up to $5 \mathrm{~mm}$ amplitude.

\section{CONCLUSIONS}

The added mass and damping introduced by pedestrians on a vertically vibrating footbridge has been determined through a series of forced vibration tests on a $16 \mathrm{~m}$ long laboratory footbridge. For all amplitudes of vibration and pedestrian flow rates, the added mass of a single pedestrian was found to be $102 \%$ of the pedestrian's mass. The damping introduced by each pedestrian was found to be positive for all amplitudes, but decreasing with increasing amplitudes of vibration. A conservative fixed value of $500 \mathrm{~kg} / \mathrm{s}$ is suggested as an individual pedestrian damping coefficient for design purposes.

\section{REFERENCES}

[1] SETRA, Footbridges, Assessment of vibrational behavior of footbridges under pedestrian loading. Technical guide, Technical Department for Transport, Road Bridges, Engineering and Road Safety. Paris, October, 2006

[2] FIB. Guidelines for the design of footbridges, bulletin 32, Fédération international du béton (fib), November 2005

[3] Georgakis, C.T., Ingólfsson, E.T. "Vertical Footbridge Vibrations: The Response Spectrum Methodology", Footbridge 2008, Porto, July 2-4, 2008

[4] S. Živanović, I. M. Díaz, A. Pavić, "Influence of Walking and Standing Crowds on Structural Dynamic Properties", IMAC-XXVII, February 9-12, 2009, Orlando, Florida, USA

[5] Clough, R.W., Penzien, J., Dynamics of Structures, McGraw-Hill, 1975, $1^{\text {st }}$ Edition

[6] Ingólfsson ET, Georgakis CT, Ricciardelli F, Jönsson J., "Experimental identification of pedestrian-induced lateral forces on footbridges", Journal of Sound and Vibration, 2011; 330:1265-84 